\title{
Micropropagation of Chinquapin (Castanea henryi) Using Axillary Shoots and Cotyledonary Nodes
}

Huan Xiong', He Sun ${ }^{1}$, Feng Zou, and Xiaoming Fan

Central South University of Forestry and Technology, Changsha 410004, Hunan, China; Key Lab of Non-wood Forest Products of State Forestry Administration; Key Laboratory of Cultivation and Protection for Non-Wood Forest Trees, Ministry of Education; and Cooperative Innovation Center of Cultivation and Utilization for Non-Wood Forest Trees of Hunan Province

\section{Genhua Niu}

Texas AgriLife Research at El Paso, Texas A\&M University System, 1380 A\&M Circle, El Paso, TX 79927

\section{Deyi Yuan ${ }^{2}$}

Central South University of Forestry and Technology, Changsha 410004, Hunan, China; Key Lab of Non-wood Forest Products of State Forestry Administration; Key Laboratory of Cultivation and Protection for Non-Wood Forest Trees, Ministry of Education; and Cooperative Innovation Center of Cultivation and Utilization for Non-Wood Forest Trees of Hunan Province

Additional index words. tissue culture, adventitious shoot, perlite, rooting

\begin{abstract}
Castanea henryi is an important woody grain tree species native to China. The objective of the current study was to find the suitable plant growth regulators (PGRs) and the optimal concentrations for direct organogenesis by using axillary shoots and cotyledonary nodes. Seeds were collected from the field, sterilized, and germinated in vitro. Axillary shoots and cotyledonary nodes of 3-week-old seedlings were used as explants. To find the suitable PGR for adventitious shoot induction, $0.5 \mathrm{mg} \cdot \mathrm{L}^{-1}$ 6-benzylaminopurine $(6-B A), 0.1 \mathrm{mg} \cdot \mathrm{L}^{-1}$ indole-3-acetic acid (IAA), $0.1 \mathrm{mg} \cdot \mathrm{L}^{-1}$ 2,4-dichlorophenoxyacetic acid (2,4-D), or $0.1 \mathrm{mg} \cdot \mathrm{L}^{-1}$ 1-naphthaleneacetic acid (NAA) was supplemented to Murashige and Skoog (MS) medium containing $0.65 \%$ agar and $3 \%$ sucrose. A high induction percentage of adventitious shoots $(85.67 \%)$ was obtained from cotyledonary nodes supplemented with $0.1 \mathrm{mg} \cdot \mathrm{L}^{-1} 2,4-\mathrm{D}$. The type of explant influenced shoot proliferation rates and quality. Apical explants produced more and longer shoots than nodal segments. For shoot multiplication, $1 \mathrm{mg} \cdot \mathrm{L}^{-1}$ 6-BA +0.05 $\mathrm{mg} \cdot \mathrm{L}^{-1}$ indole-3-butyric acid (IBA) supplemented with MS medium produced 12.33 and 6.25 shoots per explant, respectively, from apical and nodal explants. For shoot elongation and strengthening, $2 \mathrm{mg} \cdot \mathrm{L}^{-1}$ 6-BA $+0.05 \mathrm{mg} \cdot \mathrm{L}^{-1}$ IBA supplemented with MS medium was the best combination, producing shoots with a mean length of $3.50 \mathrm{~cm}$, a diameter of $0.46 \mathrm{~cm}$, and about eight leaves per shoot. The greatest rooting of $76.70 \%$ and 11.33 roots per shoot was achieved when cultured in MS medium supplemented with $3.5 \%$ perlite $+1.5 \mathrm{mg} \cdot \mathrm{L}^{-1}$ IBA. For acclimatization of the rooted plantlets in the greenhouse, a survival rate of $80 \%$ was achieved. This protocol-from multiplication to acclimation-is helpful to realize mass propagation of high-quality trees of chinquapin for increasing production and nut quality.
\end{abstract}

Chinquapin (Castanea henryi) is an economically important species of the Castanea genus that produces timber and starch, which are widely distributed in southern China, especially in the Fujian, Zhejiang, and Hunan

\footnotetext{
Received for publication 12 June 2018. Accepted for publication 27 July 2018.

This study was supported by the National Natural Science Foundation (grant no. 31500554), the Chinese National Science and Technology Pillar Program (grant no. 2013BAD14B04), and the Scientific Innovation Fund for Post-graduates of Central South University of Forestry and Technology (grant nos. 20181002 and CX2017B61).

${ }^{1}$ These authors contributed equally.

${ }^{2}$ Corresponding author. E-mail: csuftyuanyi@126. com.
}

Provinces (Fan et al., 2017; Yang et al., 2015). This deciduous tree species has been used increasingly as a woody grain because the nut has several favorable characteristics, including a high starch content of $47.58 \%$ $56.94 \%$ (Zheng et al., 2002), a high mineral nutrition content, and 18 kinds of amino acids, among which eight are good for health (Fan et al., 2015). What's more, the chinquapin nut is the main economic source for growers in southern China. To meet the demand for chinquapin nuts, in practice, grafting propagation has been used, because cutting is very difficult for Castanea species (Tetsumura and Yamashita, 2004). Micropropagation is a way of asexual production that can obtain seedlings with the same genotype in a short time and ensures genotype stability, which is even helpful for transgenic studies (Corredoira et al., 2004; Li et al., 2017; Mondal et al., 2001).

Micropropagation of Castanea species has been investigated on the American chestnut ( $C$. dentata) (Oakes et al., 2013, 2016; Xing et al., 1997, 1999), the Chinese chestnut (C. mollissima) (Lu et al., 2017; Qi-guang et al., 1986), the European chestnut (C. sativa) (Corredoira et al., 2003; Rodriguez, 1982; Sezgin and Dumanoğlu, 2014), the Japanese chestnut (C. crenata) (Tetsumura and Yamashita, 2004), and their hybrid chestnut (Cuenca et al., 2017; Vidal et al., 2015). Micropropagation of Castanea species in most of the reports was successful. To our knowledge, there have been no reports on either in vitro regeneration or successful acclimation of chinquapin.

Producing woody plants from micropropagation is an extremely time- and laborintensive process, needing many steps and various growing media (Gonçalves et al., 1998; Oakes et al., 2016; Pijut et al., 2010). Axillary shoot explants have been used to achieve regenerated plants in many species, including hybrid chestnuts (Cuenca et al., 2017; Vidal et al., 2015), Vaccinium sp. (Litwińczuk, 2013), and Salix viminalis (Regueira et al., 2018). Cotyledonary node explants were used mainly in legume crops to regenerate shoots (Abd Aziz et al., 2018), and in the woody plants $C$. sativa and Camellia oleifera, cotyledonary node explants were also a success (Li et al., 2016; San-José et al., 2001). However, to date, there has been no efficient system for the micropropagation of chinquapin by using axillary shoots and cotyledonary nodes. Therefore, the objective of this study was to establish a direct organogenesis micropropagation system by optimizing PGRs and growth conditions for explant types of axillary shoots and cotyledonary nodes.

\section{Materials and Methods}

Plant materials. Seeds of Castanea henryi cv. Huali 1 were collected from the chinquapin experimental field of Central South Forestry University of Science and Technology in Rucheng County, Chenzhou, Hunan Province (lat. $25^{\circ} 33^{\prime} \mathrm{N}$, long. $113^{\circ} 45^{\prime} \mathrm{E}$ ). Seeds were surface sterilized with sodium hypochlorite $(5 \%)$ for $15 \mathrm{~min}$. The tegument was removed and the seeds were disinfected in $75 \%(\mathrm{v} / \mathrm{v})$ ethanol for $60 \mathrm{~s}$, then rinsed three times with sterile distilled water for at least $30 \mathrm{~s}$ each time. Next, the seeds were treated with $0.1 \%(\mathrm{w} / \mathrm{v})$ mercuric chloride $\left(\mathrm{HgCl}_{2}\right)$ solution for $6 \mathrm{~min}$ and then rinsed five times with sterile distilled water to remove excess $\mathrm{HgCl}_{2}$. Excised part of the cotyledons before seed embryos was placed on aseptic MS (Murashige and Skoog, 1962) medium, which contained $0.65 \%$ agar and $3 \%$ sucrose, in glass tubes for germination. The seedlings were grown under white fluorescent lamps (50 $\left.\mu \mathrm{mol} \cdot \mathrm{m}^{-2} \cdot \mathrm{s}^{-1}\right)$ for a photoperiod/dark period of $14 \mathrm{~h} / 10 \mathrm{~h}$ at a temperature of 
$25 \pm 2{ }^{\circ} \mathrm{C}$ (Fig. 1A). Axillary shoots and cotyledonary nodes from 3 -week-old in vitro seedlings were used as explants (Fig. 1B). The culture conditions (light and temperature) were kept the same for the following described experiments

Adventitious bud induction. The cotyledonary node explants were excised from 3week-old seedlings cultured in the tube and placed on MS medium containing $0.65 \%$ agar and $3 \%$ sucrose, supplemented with 6-BA $\left(0.5 \mathrm{mg} \cdot \mathrm{L}^{-1}\right)$, IAA $\left(0.1 \mathrm{mg} \cdot \mathrm{L}^{-1}\right), 2,4-\mathrm{D}(0.1$ $\left.\mathrm{mg} \cdot \mathrm{L}^{-1}\right)$, or NAA $\left(0.1 \mathrm{mg} \cdot \mathrm{L}^{-1}\right)$ for direct adventitious shoot induction (Table 1). A total of 162 explants (54 explants per replicate) were cultured. After $30 \mathrm{~d}$, the differentiation rate of adventitious shoots was recorded (Fig. 1C-E).

Multiplication. The axillary shoots excised from 3-week-old seedlings and adventitious shoots from cotyledonary nodes, including apical and nodal explants (with two leaves and $>1.0 \mathrm{~cm}$ in height), were transferred to MS medium containing $0.65 \%$ agar and $3 \%$ sucrose, supplemented with 6-BA $\left(1,2\right.$, or $\left.3 \mathrm{mg} \cdot \mathrm{L}^{-1}\right)$, IBA $(0.05,0.2$, or $\left.0.5 \mathrm{mg} \cdot \mathrm{L}^{-1}\right)$, or gibberellic acid $\left(\mathrm{GA}_{3} ;(0\right.$, 0.05 , or $3 \mathrm{mg} \cdot \mathrm{L}^{-1}$ ) for multiplication (Table 2 ). After 4 weeks, the proliferation coefficient was calculated as follows: the number of
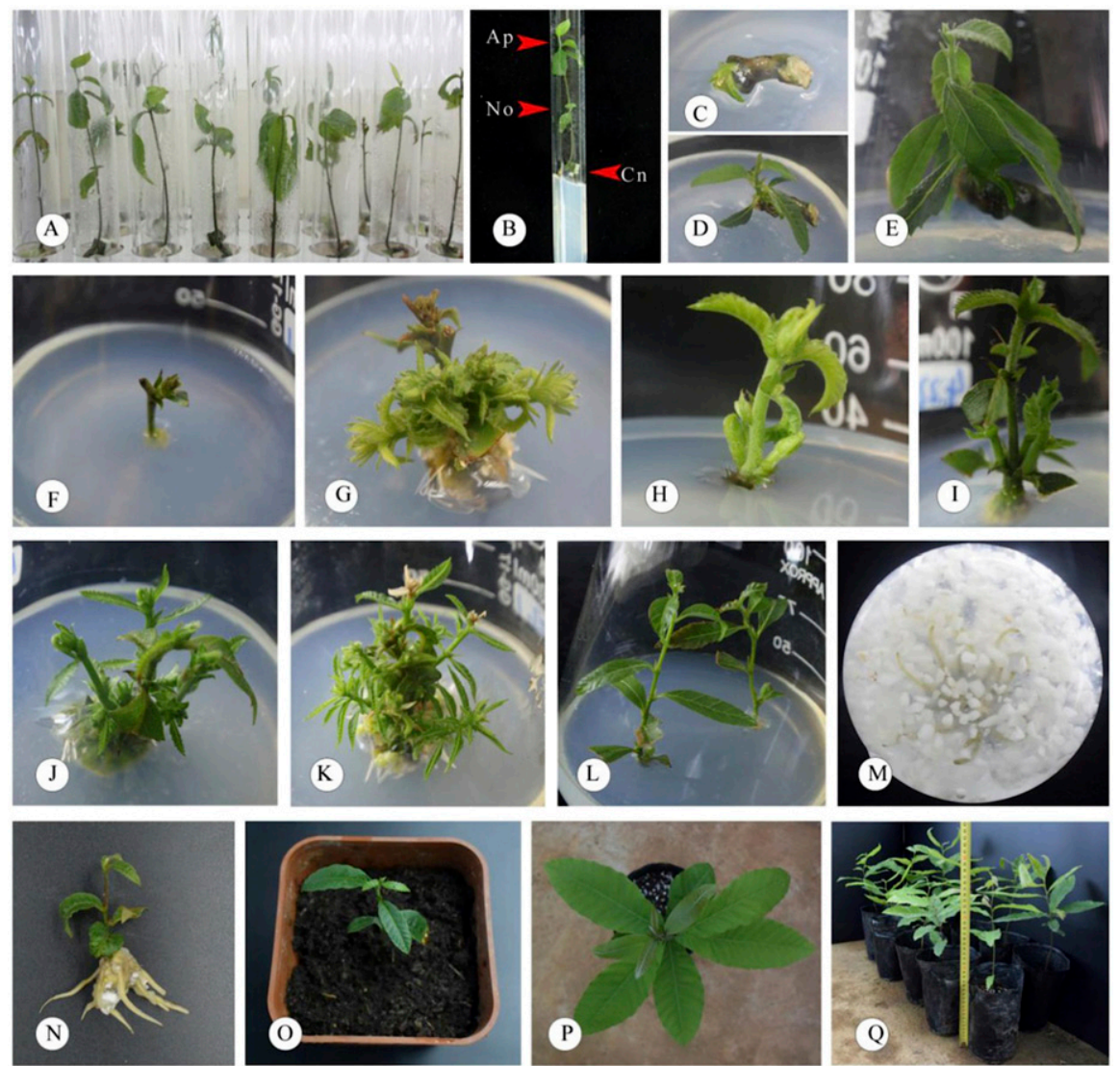

Fig. 1. Plant regeneration by using axillary shoots and cotyledonary nodes of Castanea henryi. (A, B) Aseptic seedling cultured for 3 weeks. Axillary shoots and cotyledonary nodes used as explants. Ap, apical explants; No, nodal explants; Cn, cotyledonary nodes explants. (C-E) Adventitious shoot induction from cotyledonary nodes after 1, 2, and 4 weeks. (F, G) Microshoot multiplication after 1 and 4 weeks from nodal explants. (H-K) Microshoot multiplication after 1, 2, 3, and 4 weeks from apical explants. (L) Shoot elongation and strengthening. (M, N) Rooting. (O) Rooted plantlets transferred to climate chamber after 4 weeks. (P, Q) Acclimatized plants under greenhouse conditions for 2 months. by removing the media with tap water, then planted, one plant per pot, into $6-\times 7-\mathrm{cm}$ (diameter $\times$ height) pots filled with substrate that was a mixture of peat : perlite at 2:1 (v/v), saturated with modified Melin-Norkrans liquid $\left[\mathrm{CaCl}_{2} \cdot 2 \mathrm{H}_{2} \mathrm{O} 0.05 \mathrm{~g} \cdot \mathrm{L}^{-1}, \mathrm{MgSO}_{4} \cdot 7 \mathrm{H}_{2} \mathrm{O}\right.$ $0.15 \mathrm{~g} \cdot \mathrm{L}^{-1}, \mathrm{NaCl} 0.025 \mathrm{~g} \cdot \mathrm{L}^{-1},\left(\mathrm{NH}_{4}\right)_{2} \mathrm{HPO}_{4}$ $0.25 \mathrm{~g} \cdot \mathrm{L}^{-1}, \mathrm{KH}_{2} \mathrm{PO}_{4} 0.5 \mathrm{~g} \cdot \mathrm{L}^{-1}$, vitamin $\mathrm{B} 10.1$ $\mathrm{mg} \cdot \mathrm{L}^{-1}$, citric acid $0.2 \mathrm{~g} \cdot \mathrm{L}^{-1}$, glucose $10 \mathrm{~g} \cdot \mathrm{L}^{-1}$, and $\mathrm{pH}$ adjusted to 5.5]. All pots were placed in a climate chamber with humidity at $80 \%$ for $3 \mathrm{~d}$, and dropped $5 \%$ every $3 \mathrm{~d}$ thereafter, until reaching to the same humidity as the ambient environment (about 65\%). The pots remained in the climate chamber for 1 month. Afterward, the plants were transferred to larger pots $12 \times 16 \mathrm{~cm}$ (diameter $\times$ height) and filled with a potting mix of peat:perlite: loess at 1:1:1 ( $/ \mathrm{v} / \mathrm{v})$. The pots were then placed in a greenhouse covered with a shade net and watered whenever the substrate surface was dry. Two months later, the surviving plantlets were counted and their height was recorded.

Statistical analysis. Experiments for multiplication and shoot elongation and strengthening followed an orthogonal design, whereas those for adventitious bud induction and rooting were arranged in a completely randomized design. There were three replicates for each treatment for all experiments. All data were expressed as mean value \pm SE and were subjected to analysis of variance (ANOVA) (Li et al., 2016) and nonparametric tests using SPSS 19.0 software (Chicago, IL). $P<0.05$ was considered statistically significant.

\section{Results and Discussion}

Cotyledonary node shoot induction. For shoot induction, supplementing 2,4-D at $0.1 \mathrm{mg} \cdot \mathrm{L}^{-1}$ induced adventitious shoots at $85.67 \%$ (Table 1), with thick stems and lots of leaves (Fig. 1C-E), whereas $0.1 \mathrm{mg} \cdot \mathrm{L}^{-1}$ 2,4-D combined with $0.5 \mathrm{mg} \cdot \mathrm{L}^{-1}$ 6-BA did not have any adventitious shoots; instead, a large number of compact calluses was formed. It is interesting to note that medium containing IAA induced a lot of roots but no shoots, whereas medium containing NAA induced only a few calluses.

For woody plants, using a cotyledonary node as an explant is relatively easy to promote adventitious shoots (Huang et al., 2014; Li et al., 2016; San-José et al., 2001). Therefore, adventitious shoots were restored from epidermal cells that may retain the characteristics of parenchymal cells. The number and frequency of shoot induction were dependent mainly on the concentration of cytokinin used in the culture medium (Sharma, 2017). However, 6-BA in our study could not induce any shoots but did induce some calluses when combined with NAA and 2,4D. Instead, 2,4-D, a kind of auxin, did produce adventitious shoots. It is worth investigating whether more adventitious shoots per explant might be induced under the right type of PGR and concentration by using cotyledonary nodes (Abd Aziz et al., 2018; Li et al., 
Table 1. Effects of different plant growth regulator combinations on adventitious shoot induction from cotyledonary nodes of Castanea henryi.

\begin{tabular}{|c|c|c|c|c|c|}
\hline \multicolumn{4}{|c|}{ Plant growth regulators $\left(\mathrm{mg} \cdot \mathrm{L}^{-1}\right)$} & \multirow[b]{2}{*}{ Shoot formation rate $(\%)^{\mathrm{z}}$} & \multirow[b]{2}{*}{ Description of shoot formation } \\
\hline 6-BA & IAA & $2,4-\mathrm{D}$ & NAA & & \\
\hline 0.5 & & 0.1 & & $0 \pm 0$ & Many compact calluses were induced \\
\hline \multirow{3}{*}{0.5} & 0.1 & & & $0 \pm 0$ & No adventitious bud but a lot of roots \\
\hline & & 0.1 & & $85.67 \pm 5.05$ & Healthy adventitious shoots with a lot of leaves \\
\hline & & & 0.1 & $0 \pm 0$ & Induced a few calluses \\
\hline
\end{tabular}

${ }_{\mathrm{z}}$ Values represent the mean $\pm \mathrm{SE}$ from three replicates of nine shoots each.

6-BA = 6-benzylaminopurine; IAA = indole-3-acetic acid; 2,4-D = 2,4-dichlorophenoxyacetic acid; NAA = 1-naphthaleneacetic acid.

Table 2. Effect of different plant growth regulator combinations and type of explant on shoot formation of Castanea henryi.

\begin{tabular}{|c|c|c|c|c|c|}
\hline \multicolumn{3}{|c|}{ Plant growth regulators $\left(\mathrm{mg} \cdot \mathrm{L}^{-1}\right)$} & \multirow[b]{2}{*}{ Explant type } & \multirow[b]{2}{*}{ Multiplication rate ${ }^{y, z}$} & \multirow[b]{2}{*}{ Description of proliferation } \\
\hline 6-BA & IBA & $\mathrm{GA}_{3}$ & & & \\
\hline$\overline{1}$ & & & Nodal & $6.25 \pm 0.05 \mathrm{a}$ & Light-green leaves with a large callus at the base \\
\hline 1 & 0.2 & 0.05 & Apical & $11.67 \pm 0.74 \mathrm{a}$ & Dark-green leaves with a few calluses at the base \\
\hline \multirow[t]{2}{*}{1} & 0.5 & 3 & Apical & $5.67 \pm 0.47 \mathrm{~b}$ & Dark-green leaves with a few calluses at the base \\
\hline & & & Nodal & $3.40 \pm 0.04 \mathrm{c}$ & Dark-green leaves with large callus at the base \\
\hline 2 & 0.05 & 0 & Apical & $1.18 \pm 0.15 \mathrm{~d}$ & Light-green leaves with large callus at the base \\
\hline 2 & & & Nodal & $1.70 \pm 0.06 \mathrm{f}$ & Dark-green leaves with large callus at the base \\
\hline \multirow[t]{2}{*}{2} & 0.5 & 3 & Apical & $2.21 \pm 0.11 \mathrm{~cd}$ & Light-green leaves with a few calluses at the base \\
\hline & & & Nodal & $2.14 \pm 0.03 \mathrm{~d}$ & Light-green leaves with a few calluses at the base \\
\hline \multirow[t]{2}{*}{3} & 0.05 & 0 & Apical & $1.52 \pm 0.08 \mathrm{~d}$ & Light-green leaves with large callus at the base \\
\hline & & & Nodal & $1.75 \pm 0.04 \mathrm{f}$ & Light-green leaves with a few calluses at the base \\
\hline \multirow[t]{2}{*}{3} & 0.2 & 0.05 & Apical & $1.11 \pm 0.08 \mathrm{~d}$ & Dark-green leaves with no callus at the base \\
\hline & & & Nodal & $1.10 \pm 0.05 \mathrm{~g}$ & Light-green leaves with a few calluses at the base \\
\hline
\end{tabular}

${ }^{\mathrm{z}}$ Multiplication rate $=$ no. of shoots after induction/no. of axillary shoots before induction.

${ }^{\mathrm{y}}$ Values represent the mean \pm SE from three replicates of nine shoots each. Different letters followed the mean indicate significance at $P<0.05$ according to Duncan's multiple range test.

6-BA = 6-benzylaminopurine; IBA = indole-3-butyric acid; $\mathrm{GA}_{3}=$ gibberellic acid.

Table 3. Effect of different plant growth regulator combinations on shoot elongation and strengthening of Castanea henryi.

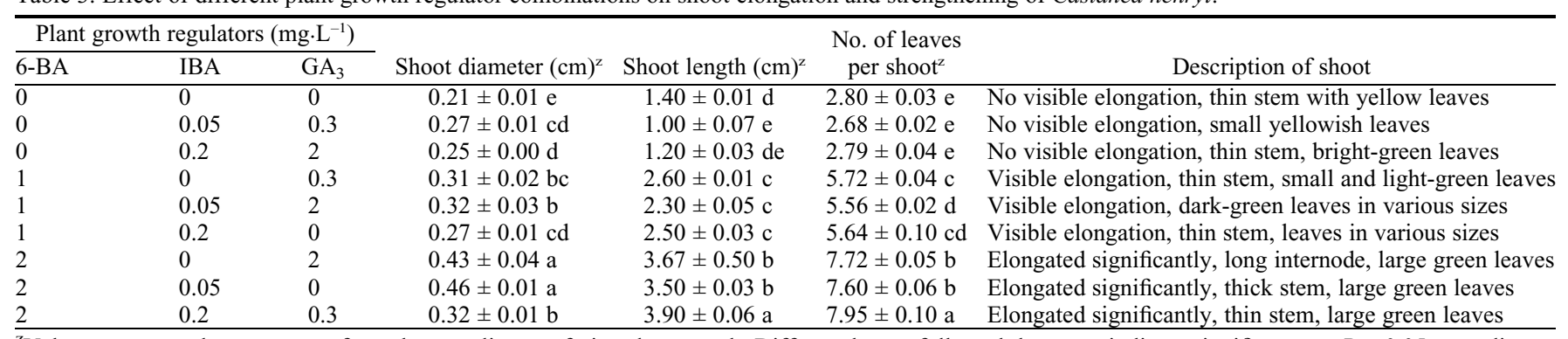

${ }^{\mathrm{z}}$ Values represent the mean $\pm \mathrm{SE}$ from three replicates of nine shoots each. Different letters followed the mean indicate significance at $P<0.05$ according to Duncan's multiple range test.

6-BA = 6-benzylaminopurine; IBA = indole-3-butyric acid; $\mathrm{GA}_{3}=$ gibberellic acid.

2016), considering the number was low in this study (data not shown).

Apical and nodal explant proliferation rates. Multiplication rates of apical and nodal explants are shown in Table 2 and Fig. $1 \mathrm{~F}-\mathrm{K}$. Both types of explant, the PGR, and their interaction influenced shoot multiplication rates $(P<0.0001)$. The apical explants produced more and longer shoots than nodal segments (Table 2; Fig. $1 \mathrm{G}$ and $\mathrm{K}$ ). For apical explants, there was no significant difference in multiplication rates between the combination of $1 \mathrm{mg} \cdot \mathrm{L}^{-1} 6-\mathrm{BA}+0.05 \mathrm{mg} \cdot \mathrm{L}^{-1} \mathrm{IBA}$ and $1 \mathrm{mg} \cdot \mathrm{L}^{-1} 6-\mathrm{BA}+0.02 \mathrm{mg} \cdot \mathrm{L}^{-1}$ IBA +0.05 $\mathrm{mg} \cdot \mathrm{L}^{-1} \mathrm{GA}_{3}$. The multiplication rate was 12.33 and 11.67 , respectively. For nodal segments, the greatest multiplication rate (6.25) was obtained with $1 \mathrm{mg} \cdot \mathrm{L}^{-1} 6-\mathrm{BA}+0.05 \mathrm{mg} \cdot \mathrm{L}^{-1}$ IBA. All combinations of PGR in this study produced multiple shoots, with the multiplication rate ranging from 1.08 to 12.33 . The multiplication rate decreased when 6-BA concentration was greater than $1 \mathrm{mg} \cdot \mathrm{L}^{-1}$. The multiplication rate decreased when the IBA and $\mathrm{GA}_{3}$ concentration increased.

A high multiplication rate is an important indicator for assessing a regeneration system. The influence of the position of axillary shoots on shoot quality and multiplication rates has been studied in hybrid chestnut (Vidal et al., 2015). Vidal et al. (2015) found that the apical explants in clone 90025 obtained a greater multiplication rate (3.7) and a longer shoot $(3.4 \mathrm{~cm})$ than nodal explants (2.1 and $1.9 \mathrm{~cm}$, respectively). The current study also showed that apical explants produced more and longer shoots than nodal segments.

A combination of cytokinin and auxin has been proved to be efficient for woody plant shoot proliferation ( $\mathrm{Li}$ et al., 2016; Mathur et al., 2002; Siwach and Gill, 2011). Moreover, 6-BA has been well documented as an efficient inducer for shoot multiplication in many woody plants, including American and European chestnuts (Asthana et al., 2011; Bunn, 2005; Rodriguez, 1982; Xing et al., 1997). But, it was also reported that a greater concentration of 6-BA was inhibitory in some woody plants, such as Prunus armenica cv. Canino (Tornero et al., 2000) and Pterocarpus 
Table 4. Effect of medium and different plant growth regulator combinations on rooting performance of Castanea henryi.

\begin{tabular}{|c|c|c|c|c|c|c|}
\hline \multirow[b]{2}{*}{ Medium } & \multicolumn{2}{|c|}{ Plant growth regulators $\left(\mathrm{mg} \cdot \mathrm{L}^{-1}\right)$} & \multirow[b]{2}{*}{ Rooting rate $(\%)^{\mathrm{z}}$} & \multirow[b]{2}{*}{ No. of roots ${ }^{z}$} & \multirow[b]{2}{*}{ Length of roots $(\mathrm{cm})$} & \multirow[b]{2}{*}{ Description of root growth } \\
\hline & IBA & NAA & & & & \\
\hline $\mathrm{MS}$ & 0.1 & & $16.70 \pm 1.14 \mathrm{e}$ & $1.67 \pm 0.05 \mathrm{~d}$ & 0.50 & Thin roots \\
\hline MS & 0.5 & & $23.30 \pm 0.88 \mathrm{c}$ & $2.67 \pm 0.17 \mathrm{c}$ & 3.00 & Thick roots \\
\hline MS & 1.5 & & $76.70 \pm 0.42 \mathrm{a}$ & $11.33 \pm 0.47 \mathrm{a}$ & 4.00 & White roots with a few calluses at base \\
\hline $1 / 2 \mathrm{MS}$ & 0.1 & & $6.70 \pm 0.19 \mathrm{f}$ & $1.33 \pm 0.05 \mathrm{~d}$ & 0.50 & Thin roots \\
\hline $1 / 2 \mathrm{MS}$ & 0.5 & & $20.00 \pm 0.71 \mathrm{~d}$ & $1.33 \pm 0.03 \mathrm{~d}$ & 5.00 & Thick roots with a lot of calluses at base \\
\hline $1 / 2 \mathrm{MS}$ & 1.5 & & $63.30 \pm 0.51 \mathrm{~b}$ & $6.33 \pm 0.12 b$ & 3.50 & Thick roots with a few calluses at base \\
\hline MS & & 0.1 & $0 \pm 0$ & $0 \pm 0$ & 0 & No roots \\
\hline MS & & 0.5 & $0 \pm 0$ & $0 \pm 0$ & 0 & No roots \\
\hline MS & & 1.5 & $0 \pm 0$ & $0 \pm 0$ & 0 & No roots \\
\hline $1 / 2 \mathrm{MS}$ & & 0.1 & $0 \pm 0$ & $0 \pm 0$ & 0 & No roots \\
\hline 1/2MS & & 0.5 & $0 \pm 0$ & $0 \pm 0$ & 0 & No roots \\
\hline 1/2MS & & 1.5 & $0 \pm 0$ & $0 \pm 0$ & 0 & No roots \\
\hline
\end{tabular}

${ }^{\mathrm{z}}$ Values represent the mean \pm SE from three replicates of nine shoots each. Different letters followed the mean indicate significance at $P<0.05$ according to Duncan's multiple range test.

MS = Murashige and Skoog medium; IBA = indole-3-butyric acid; NAA = 1-naphthaleneacetic acid.

santalinus (Balaraju et al., 2011). The current $\mathrm{t}$ study confirmed the 6-BA effect in multiplication and was in agreement that a greater concentration of 6-BA was inhibitory for C. henryi.

Shoot elongation and strengthening. Different PGR combinations influenced shoot elongation and strengthening: nonparametric tests at $P=0.006$ and $P=0.002$, respectively, for diameters and lengths; and ANOVA at $P<0.0001$ for the number of leaves per shoot. There was no visible elongation and strengthening without 6-BA. With increasing 6-BA concentration, shoot elongation and strengthening were more obvious. However, using a constant 6-BA concentration produced no significant difference in shoot elongation and strength with changes in the concentrations of IBA and $\mathrm{GA}_{3}$ (Table 3). Considering shoot growth, MS medium supplemented with 2 $\mathrm{mg} \cdot \mathrm{L}^{-1}$ 6-BA and $0.05 \mathrm{mg} \cdot \mathrm{L}^{-1}$ IBA was the best combination for shoot elongation and strengthening, with a mean length of $3.50 \mathrm{~cm}$, a diameter of $0.46 \mathrm{~cm}$, and about eight leaves per shoot (Fig. 1L).

Our study indicated that 6-BA concentration played an important role in shoot elongation and strengthening. With the appropriate cytokinin and auxin concentration, chinquapin shoots were strong enough for rooting and surviving after potting ex vitro. As the study on the American chestnut showed that in vitro shoots are recommended only if they have more than six leaves before rooting and are greater than $3 \mathrm{~cm}$ in height so they would be large enough to survive after potting (Oakes et al., 2016).

Rooting. Both MS medium strength and type of PGR, and their interaction influenced rooting significantly $(P<0.0001)$. Adding IBA to the medium produced roots regardless of concentration, whereas adding NAA only led to calluses at the base of the shoots (Table 4). IBA concentration influenced rooting rate and number of roots significantly. With the increasing concentration of IBA, rooting percentage increased. Compared with half-strength MS, full-strength MS improved rooting rate and the number of roots significantly (Table 4). MS medium combined with $3.5 \%$ perlite and $1.5 \mathrm{mg} \cdot \mathrm{L}^{-1}$ IBA led to a rooting rate as much as $76.70 \%$, and strong plantlets for acclimatization.
For Castanea species, in vitro rooting is a bottleneck in micropropagation. In our study, visible adventitious roots were induced in 2 weeks and, 4 weeks later, plantlets could be taken from the rooting medium for acclimatization (Fig. 1M and N). However, a previous study on American chestnut showed that plantlet survival in the growth chamber could be improved dramatically by shortening the time in rooting medium from 8 to $10 \mathrm{~d}$ to 3 to $4 \mathrm{~d}$, and also by placing plantlets in the dark during this time (Oakes et al., 2013). The results of that study indicated that there is potential for shortening the rooting phase and improving the survival rate during acclimatization for chinquapin micropropagation. Adding perlite to rooting medium improved root induction in $C$. oleifera (Li et al., 2016). Similarly, the rooting rate in our study was acceptable by using perlite in the rooting medium. It has been reported that halfstrength MS or quarter-strength MS with the appropriate auxin was more useful than fullstrength MS for inducing root growth, as seen in Llex crenata and C. oleifera, indicating that lowconcentration inorganic salt was better for rooting and root development (Dong et al., 2017; Li et al., 2016; Yang et al., 2015). However, in our study, full-strength MS was much better than half-strength $2 \mathrm{MS}$ for rooting, which was consistent with the study on red sanders (Pterocarpus santalinus) (Balaraju et al., 2011). As our results show, IBA can produce roots regardless of concentration, whereas NAA only led to the development of calluses at the base of shoots. These results are consistent with previous studies that indicated that NAA had a lesser effect on root formation than IBA ( $\mathrm{Li}$ et al., 2016; Lin et al., 2016).

Acclimatization. Of the 44 plants, 39 survived the transplant from in vitro to the growth chamber (Fig. 1O); five withered after 1 month. Two months after acclimatization in the greenhouse, $80 \%$ of plants survived, with a mean plant height of $20 \mathrm{~cm}$ (Fig. 1Q).

\section{Conclusion}

Adventitious shoots were induced with a high induction rate by supplementing with $0.1 \mathrm{mg} \cdot \mathrm{L}^{-1} 2,4-\mathrm{D}$ to $\mathrm{MS}$ medium, and apical explants produced more and longer shoots than nodal segments. For shoot multiplication, a combination of $1 \mathrm{mg} \cdot \mathrm{L}^{-1} 6-\mathrm{BA}+0.05$ $\mathrm{mg} \cdot \mathrm{L}^{-1}$ IBA added to MS medium was recommended using either apical or nodal explants. For shoot elongation and strengthening, $2 \mathrm{mg} \cdot \mathrm{L}^{-1} 6-\mathrm{BA}+0.05 \mathrm{mg} \cdot \mathrm{L}^{-1} \mathrm{IBA}$ added to MS medium was the best combination. The greatest rooting of $76.70 \%$ and 11.33 roots per shoot were achieved by adding $1.5 \mathrm{mg} \cdot \mathrm{L}^{-1}$ IBA to the rooting medium; the rooting percentage increased with IBA concentration. For acclimatization of the rooted plantlets in the greenhouse, a survival rate of $80 \%$ was achieved. This protocol will be helpful in realizing mass propagation of high-quality trees of chinquapin for high yield and nut quality.

\section{Literature Cited}

Abd Aziz, N., B.C. Tan, R.Y. Othman, and N. Khalid. 2018. Efficient micropropagation protocol and genome size estimation of an important cover crop, Mucuna bracteata DC. ex Kurz. Plant Cell Tissue Organ Cult. 132:267278.

Asthana, P., V.S. Jaiswal, and U. Jaiswal. 2011. Micropropagation of Sapindus trifoliatus L. and assessment of genetic fidelity of micropropagated plants using RAPD analysis. Acta Physiol. Plant. 33:1821-1829.

Balaraju, K., P. Agastian, S. Ignacimuthu, and K. Park. 2011. A rapid in vitro propagation of red sanders (Pterocarpus santalinus L.) using shoot tip explants. Acta Physiol. Plant. 33:2501-2510.

Bunn, E. 2005. Development of in vitro methods for ex situ conservation of Eucalyptus impensa, an endangered mallee from southwest Western Australia. Plant Cell Tissue Organ Cult. 83:97102.

Corredoira, E., A. Ballester, and A.M. Vieitez. 2003. Proliferation, maturation and germination of Castanea sativa Mill. somatic embryos originated from leaf explants. Ann. Bot. 92:129-136.

Corredoira, E., D. Montenegro, M.C. San-José, A.M. Vieitez, and A. Ballester. 2004. Agrobacteriummediated transformation of European chestnut embryogenic cultures. Plant Cell Rep. 23:311318.

Cuenca, B., C. Sánchez, A. Aldrey, B. Bogo, B. Blanco, B. Correa, and N. Vidal. 2017. Micropropagation of axillary shoots of hybrid chestnut (Castanea sativa $\times$ C. crenata) in liquid 
medium in a continuous immersion system. Plant Cell Tissue Organ Cult. 131:307-320.

Dong, C., X. Li, Y. Xi, and Z.M. Cheng. 2017. Micropropagation of Pyracantha coccinea. HortScience 52:271-273.

Fan, X., D. Yuan, J. Tang, X. Tian, L. Zhang, F. Zou, and $\mathrm{X}$. Tan. 2015. Sporogenesis and gametogenesis in Chinese chinquapin (Castanea henryi (Skam) Rehder \& Wilson) and their systematic implications. Trees (Berl.) 29:17131723.

Fan, X., D. Yuan, X. Tian, Z. Zhu, M. Liu, and H. Cao. 2017. Comprehensive transcriptome analysis of phytohormone biosynthesis and signaling genes in the flowers of Chinese chinquapin (Castanea henryi). J. Agr. Food Chem. 65:1033210349.

Gonçalves, J.C., G. Diogo, and S. Amâncio. 1998. In vitro propagation of chestnut (Castanea sativa $\times C$. crenata): Effects of rooting treatment on plant survival, peroxidase activity and anatomical changes during adventitious root formation. Scientia Hort. 72:265-275.

Huang, H., J.C. Li, K.X. OuYang, X.H. Zhao, P. Li, B.Y. Liao, and X.Y. Chen. 2014. Direct adventitious shoot organogenesis and plant regeneration from cotyledon explants in Neolamarckia cadamba. Plant Biotechnol. 31:115-121.

Li, S., Y. Cong, Y. Liu, T. Wang, Q. Shuai, N. Chen, J. Gai, and Y. Li. 2017. Optimization of Agrobacterium-mediated transformation in soybean. Front. Plant Sci. 8:246-261.

Li, Z., X. Tan, Z. Liu, Q. Lin, L. Zhang, J. Yuan, Y. Zeng, and L. Wu. 2016. In vitro propagation of Camellia oleifera Abel. using hypocotyl, cotyledonary node, and radicle explants. HortScience 51:416-421.

Lin, Q., Z. Li, L. Zhang, X.-F. Tan, H.-X. Long, and L.-L. Lu. 2016. High-efficiency regeneration of seedlings from hypocotyl explants of tung tree (Vernicia fordii). Intl. J. Agr. Biol. 18:370-376.

Litwińczuk, W. 2013. Micropropagation of $\mathrm{Vacci}$ nium sp. by in vitro axillary shoot proliferation. Methods Mol. Biol. 11013:63-76.

Lu, D., W. Wei, W. Zhou, L.D. McGuigan, F.-Y. Ji, X. Li, Y. Xing, Q. Zhang, K.-F. Fang, Q.-Q. Cao, and L. Qin. 2017. Establishment of a somatic embryo regeneration system and expression analysis of somatic embryogenesisrelated genes in Chinese chestnut (Castanea mollissima Blume). Plant Cell Tissue Organ Cult. 130:601-616.

Mathur, S., G.S. Shekhawat, and A. Batra. 2002. Micropropagation of Salvadora persica Linn. via cotyledonary nodes. Indian J. Biotechnol. 1:197-200.

Mondal, T.K., A. Bhattacharya, P.S. Ahuja, and P.K. Chand. 2001. Transgenetic tea (Camellia sinensis (L.) O. Kuntze cv. Kangra Jat) plants obtained by Agrobacterium-mediated transformation of somatic embryos. Plant Cell Rep. 20:712-720.

Murashige, T. and F. Skoog. 1962. A revised medium for rapid growth and bioassays with tobacco tissue cultures. Physiol. Plant. 15:473497.

Oakes, A.D., T. Desmarais, W.A. Powell, and C.A. Maynard. 2016. Improving rooting and shoot tip survival of micropropagated transgenic american chestnut shoots. HortScience 51:171-176.

Oakes, A.D., W.A. Powell, and C.A. Maynard. 2013. Doubling acclimatization survival of micropropagated American chestnuts with darkness and shortened rooting induction time. J. Environ. Hort. 31:77-83.

Pijut, P.M., K.E. Woeste, and C.H. Michler. 2010. Promotion of adventitious root formation of difficult-to-root hardwood tree species, p. 213251. In: J. Janick (ed.). Horticultural reviews. Wiley, Hoboken, NJ.

Qi-guang, Y., P.E. Read, C.D. Fellman, and M.A. Hosier. 1986. Effect of cytokinin, IBA, and rooting regime on Chinese chestnut cultured in vitro. HortScience 21:133-134.

Regueira, M., E. Rial, B. Blanco, B. Bogo, A. Aldrey, B. Correa, E. Varas, C. Sánchez, and N. Vidal. 2018. Micropropagation of axillary shoots of Salix viminalis using a temporary immersion system. Trees (Berl.) 32:61-71.

Rodriguez, R. 1982. In vitro propagation of Castanea sativa Mill. through meristem-tip culture. HortScience 17:888-889.

San-José, M.C., A. Ballester, and A.M. Vieitez. 2001. Effect of thidiazuron on multiple shoot induction and plant regeneration from cotyledonary nodes of chestnut. J. Hort. Sci. Biotechnol. 76:588-595.

Sezgin, M. and H. Dumanoğlu. 2014. Somatic embryogenesis and plant regeneration from immature cotyledons of European chestnut (Castanea sativa Mill.). In Vitro Cell. Dev. Biol. Plant 50:58-68.

Sharma, H. 2017. Role of growth regulators in micropropagation of woody plants: A review. Intl. J. Adv. Res. (Indore) 5:2378-2385.

Siwach, P. and A.R. Gill. 2011. Enhanced shoot multiplication in Ficus religiosa L. in the presence of adenine sulphate, glutamine and phloroglucinol. Physiol. Mol. Biol. Plants 17:271-280.

Tetsumura, T. and K. Yamashita. 2004. Micropropagation of Japanese chestnut (Castanea crenata Sieb. et Zucc.) seedlings. HortScience 39:1684-1687.

Tornero, O.P., J.M. Lopez, J. Egea, and L. Burgos. 2000. Effect of basal medium and growth regulators on the in vitro propagation of apricot (Prunus armenica L.) cv. Canino. J. Hort. Sci. Biotechnol 75:283-286.

Vidal, N., B. Blanco, and B. Cuenca. 2015. A temporary immersion system for micropropagation of axillary shoots of hybrid chestnut. Plant Cell Tissue Organ Cult. 123:229-243.

Xing, Z., W.A. Powell, and C.A. Maynard. 1999. Development and germination of American chestnut somatic embryos. Plant Cell Tissue Organ Cult. 57:47-55.

Xing, Z., M.F. Satchwell, W.A. Powell, and C.A. Maynard. 1997. Micropropagation of American chestnut: Increasing rooting rate and preventing shoot-tip necrosis. In Vitro Cell. Dev. Biol. Plant 33:43-48.

Yang, Y., D. Zhang, Z. Li, X. Jin, and J. Dong. 2015. Immature embryo germination and its micropropagation of Ilex crenata thunb. HortScience 50:733-737.

Zheng, C., X. Zhang, N. Huang, and Y. Jiang. 2002. Preliminary study on analyses of nutrient ingredients in nuts of different chinquapin (Castanea henryi) cultivars. Yaredai Zhiwu Kexue 31:5-8. (in Chinese with English abstract). 